\title{
Research on the Value of Mental Exercise from the "Trust System" of Sports in Chinese Universities
}

\author{
Li Pengsong ${ }^{1}$, Zhang Yu ${ }^{1,2, *}$, Kaspar R. Davis ${ }^{3}$ \\ ${ }^{1}$ Department of Physical Education, Dalian University of Technology, Dalian, China \\ ${ }^{2}$ State Key Laboratory of Fine Chemicals, Dalian R \& D Center for Stem Cell and Tissue Engineering, Dalian University of Technology, Dalian, \\ China \\ ${ }^{3}$ DUT Department of Foreign Studies, Dalian, China
}

Email address:

zhangyu0705@dlut.edu.cn (Zhang Yu)

${ }^{*}$ Corresponding author

\section{To cite this article:}

Li Pengsong, Zhang Yu, Kaspar R. Davis. Research on the Value of Mental Exercise from the "Trust System" of Sports in Chinese Universities. Science Journal of Public Health. Vol. 4, No. 6, 2016, pp. 489-493. doi: 10.11648/j.sjph.20160406.22

Received: November 2, 2016; Accepted: November 22, 2016; Published: November 24, 2016

\begin{abstract}
This article adopted research methods such as documentary, investigation, interview, logical analysis, and reasoning to study the feasibility of "trust" games promoted in sports teaching in Chinese colleges and universities. Results showed that "trust system" games were more easily accepted by students compared with ordinary teaching competitions, and more easily promoted and popularized in our colleges and universities. Various conditions in current colleges and universities are all conducive to carrying out "trust system" games.
\end{abstract}

Keywords: Trust System, Mental Exercise, In Sports, In College, In China

\section{Introduction}

"Trust system" is a kind of game system based on mutual trust among players. There is no referee who enforces the rules referred to as the "honor system", and this is why it is called a "trust system". Trust is regarded as dependency in the science of social psychology. Trustworthy individuals or groups mean that they seek practical policy, code of ethics, law and other previous commitments. Social exchange theory indicates that the essence of interpersonal communication depends on the both sides of the relationship between the cost and the profit. The interdependent relationship of two parties in a" trust system" means exchange, no matter what the content of the exchange are. Both sides express that they, at least, have some degree of related interest, or rely on each other to achieve his benefit. At this level, two sides have both the relationship of cooperation and competition. Cooperation and competition are interrelated dialectical unification. Competition exists in cooperation, which is the premise of competition.

Without cooperation in the competition composition, the relationship is weak and feeble or disruptive; and further it is lack of activity and lifelessness without encouraging cooperation under the condition of competing. By not paying attention to competition but only cooperation, and not paying attention to cooperation, the competition is unable to proceed. In competition and cooperation, both sides must be clear and abide by the rules, and the purpose of the rules needs to be more obvious. The traditional rules of the game are based on implied terms, and the participants have to accept the results of the competition. The referee who has the power of decision is the executor of the competition and the highest power, but the players compared to the referee are not equal at all. The relationship between the two sides is only competitive. However, the referee may also make subjective mistake, and make a unfair decision in accordance with wrong judgment. If the referee's decision is based on malicious or gross negligence, it not only violates the relevant rules of the game, but also is in violation of legal obligations [3]. For example western gymnastics, swimming, soccer, basketball, boxing; Asian martial arts and Judo [1], the antagonism decides the trust of "the participants" in traditional sports, social norms are ignored. Therefore, some sports groups and athletes acquire moral and material interests in the games, thus they violate the rules of the game, which is prohibited by law and unnecessary 
damage [2]. Athletes do not have a good code of conduct. Moreover, a "trust system" offsets the shortcoming of traditional systems of competition, which is that the contestants efforts are more active in enhancing the games fairness, and to make sports more humanize [4].

\section{The Value of the Psychological Exercise}

In China, with the rapid development of today's society, the level of trust between the people is also more likely to be low.
College students, as a sensitive social group, feel this kind of change more intensely. Under the influence of the current social situation, Xin Ziqiang and others [5] according to the trust level of college students showed that: (1) our students' interpersonal trust level decreased significantly from the years 1998 to 2009. Pang Tongtong and colleges [6] also found that college students' interpersonal trust level was gradually reduced year by year. Some scholars believe that, compared to junior high school and high school students, interpersonal trust level of college students is the lowest.

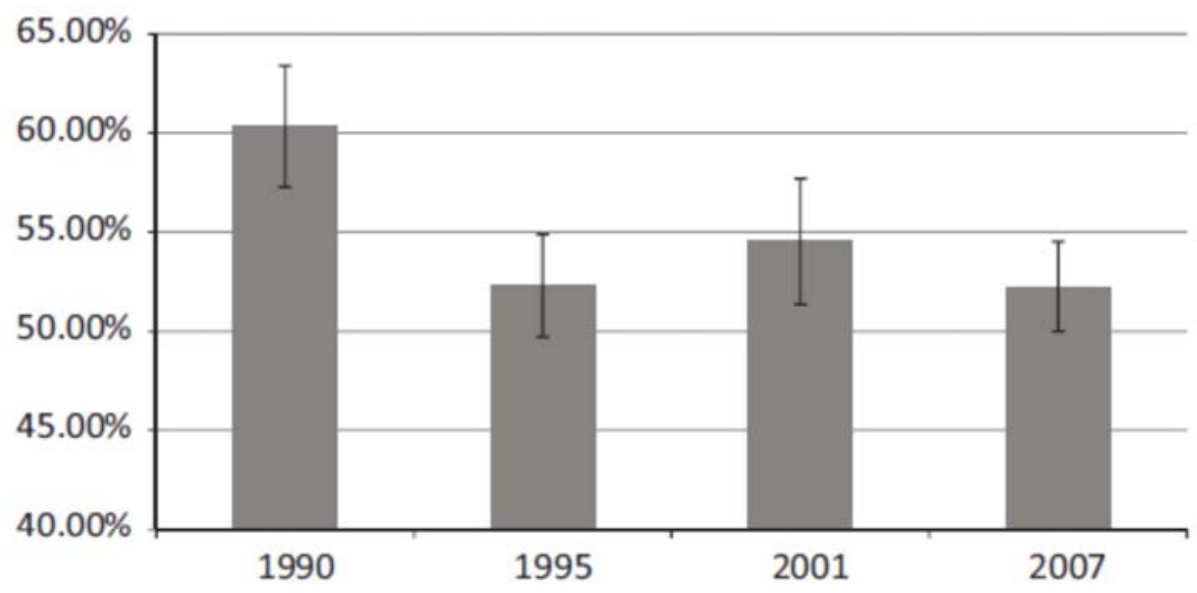

Data source: the World Values Survey 1990, 1995, 2001, and 2007

Note: Percentage of cases who state "most people are trustworthy." $95 \%$ confidence intervals are reported.

Figure 1. Descriptive tendency of generalized trust in mainland China [5].

Interpersonal trust is established by interpersonal interaction during the process of communicating with words, commitment and an expected degree of reliability in written or oral statements. The students problem with interpersonal trust is the lack of confidence in their peers. They think that others are not genuinely concerned about them, and so they are hostile to others. Doubt is the core cognitive component of distrust and it causes negative assumptions in evaluating others' psychological state during communication [8]. The sense of distrust will lead to individual negative emotions, such as self incompatibility, lack of a sense of security, lower subjective well-being and self identity confusion, which affects mental health. Therefore, it is seriously important to reconsider and bolster college students' interpersonal trust levels [9].

Xia Mian and colleagues [10] concluded that when college students' interpersonal trust levels were improved, college students' helping behavior was improved. At the same time, in a low interpersonal trust group, mindset and helping behavior associated with the degree of the sense of security is higher [11]; In groups with higher interpersonal trust, the state of empathy and helping behavior is higher. Research has shown that participating in school activities significantly increased college students' general trust and universal trust [12]. Using a "trust system" as a competition system is established on the basis of mutual trust between rivals, namely to construct a platform for increasing "trust". Some scholars [13] give college students advice on how to improve interpersonal trust management, which is to improve the interpersonal system, to establish a fair, open and transparent system of rules. Obviously, sports competitions with fair open and widely recognized rule system is an appropriate way. Researchers found [14] that, by the end of the training project, those who participated obtained higher interpersonal trust levels than those who did not. Interpersonal trust level of 18 to 25 year old participants was higher than before the experiment.

Physical exercise may induce positive thinking and emotions, and help cope with depression, anxiety and confusion, resisting in a negative state of mind (Northetal, 1990). The "trust system" greatly encourages the participants' subjective initiative and self-discipline. The contestants respectively undertake the role of the games players and referees. The "trust system" games difficulty, risk, degree of cooperation, and degree of interest are the main external stressors. Training subjects through observation, memory, imagination, collaborative cognitive activities such as active participation in the competition, complete the challenge. Based on college students' interpersonal trust problems stated above, and them being at a pivotal age of physiological and psychological development, college students are facing 
competition and increasing pressure from society, whether it is academic, financial, social or professional. Handing the aforementioned pressures requires good interpersonal relationships, and interpersonal relationships also need certain interpersonal skills to sustain them. These problems show us the importance of better handling interpersonal relationships between college students, and promoting exchanges between students. Declining interpersonal communication obstructs college students' study, emotional health and other aspects of life, and brings a series of negative effects. Improving interpersonal skills and creating good interpersonal relationships is also becoming a real problem. Some scholars believe sports are a solution to this problem. They focus on sports to improve college students' interpersonal trust and demonstrate the importance of interpersonal communication. For example, researchers in Xiamen used questionnaires to survey college basketball player positive emotions and current interpersonal trust levels. The results show that the students who participate in sports in all aspects of life had higher levels at positive emotions and interpersonal trust [15]. Researchers concluded that sports could improve college students' interpersonal skills and their ability to adapt to living environments both inside and outside of school [16]. Cheerleading training for female students may effectively promote their mental health and reduce social anxiety. [17] Improving the level of trust and cooperation, and promoting healthy psychological development [18]. The sports teams, the interpersonal relationship with the competition have higher level of solidarity, and thus athletes and their teammates have a mutual influence relationship based on trust and team performance [20]. Even in studies using prescribed sports as a means of intervention, the physical exercise along with a combination of comprehensive counseling has shown that college students' social anxiety, social avoidance and social distress have made positive changes in the overall level of mental health [21].

With the rapid development of modern society, people's working and life rhythm is faster and faster, the competition among people are becoming more and more fierce, and so work and life possess more and more uncertainties. This can cause interpersonal tension, jealousy, resentment, and otherwise undesirable moods. As a unique social activity, sports reflect social interpersonal relationships. A common activity, that allows people to know each other, and produces emotional response. Actual sports, not on the internet, but face to face, usually help people relieve trouble, tension, depression and other bad moods. This form of social support is easy for college students to get involved in. Through mutual experience, sports shorten the psychological distances between people, and promotes mutual understanding and communication.

In conclusion, sports helps participants establish equality, close and harmonious interpersonal relationships and build a more harmonious society and harmonious interpersonal relationships which is of great importance in the process of achieving happiness [22]. Generally, college students have large rate of participation in sports classes. The average university requires compulsory sports courses for freshmen and sophomores. Outdoor sports are given priority within the project in Dalian university of technology, for example, freshman students will take a general fitness course during their first semester, their next three semesters they will study various sports. Mastering the rules and providing strong base from which to participate in the "trust" game.

\section{The Value of Students' Self Control Ability}

As for "trust system" competition, it all depends on college students self control. For college students, self-control is the purpose of the game which can be realized throughout the course of the game. In carrying out a "trust system" competition, the system already conveys the message to players that I trust you, you are trustworthy. Meanwhile, in the field of management and education, the subjects of management or education experiments were given expectations and the opportunity, often achieved positive results. That effect is called "expectation effect" or Pygmalion effect. Also, the students may inwardly practice more, enhancing self-control, because the organizers of the competition in the system of the competition give the expectations. The rules in "trust system" mentioned: "in addition to the requirements, any player can't question calls made or report the other side. Rules exist for avoiding conflict and greatly reduce the conflict on the pitch, and the possibility of hostile situations". Thus, they greatly reduce the probability of hostile moods. Many roles, such as the referee, linesman, assistant referee, are dispensed with in the "trust" game, eliminating fundamentally unfair discrimination from the possibility of a handicapper and the hostility caused by identifying injustice. Pioneers of personality education believed that if the competitors were able to trust each other in the competition system and in any game relevant aspects, then participants would understand that "trust" was the core of the trust game, and participating students could place more emphasis on their personal gains and losses. Nowadays in China, there is more focusing on results, otherwise ignoring secondary gains. Anxiety and depression are extremely common. Focusing on results and ignoring personality development is a widespread practice. "Trust" games are a method to challenge these habits. They are promising way to develop the college student self-control ability in the future.

\section{4. "Trust System" Competition System Feasibility Analysis}

Zhang wei (1997) who was one of the earliest to focus on tennis competition in the United States, translated Tennis Competition manuals which allowed Chinese to become familiar with trust system. At present, several organizations have their players participate in "trust" games throughout China, especially in junior tennis. The results have been favorable and put tested into practice. In order to better 
understand distinction between the trust system and normal

(Table 1). game rules, the following table will use tennis as an example

Table 1. The difference between the tennis "trust system" and the general rules of the game.

The rules of the common game
The referee, linesman and assistant referee are responsible for judging a foot fault
The referee can make calls online, if the line number is not many, then the referees
should take to determine the fault line and out of bounds. If there is no foot wrong
referee, the referee should be responsible for the decision.
The referee, linesman and referee are responsible for judging a foot fault
The referee, linesman and referee is responsible for judging a foot fault
You can challenge the referee, and you can apply to a higher referee for a ruling
The referee, linesman and referee is responsible for judging a foot fault
The referee or the chief judge may defer the competition due to light, the location
or weather conditions.
Caddy is responsible for extra balls.
Caddy is responsible to stray balls
If athletes can not control themselves, the referee may decide to suspend the
game.

The basic rules of "trust system"

Each player is responsible for calls on their own half

When the athletes determine in or out of bounds, they do not allow the audience to help.

All "out of bounds" or "mistakes in serving" are quickly called, and loudly enough for the opponent to hear.

If the athlete can not accurately judge the placement of the ball, they must call in favor of their opponent decisions. If two people disagree on the ball, the ball is good ball.

Unless asked, an athlete can not call other side's question. Any call report, such as "out of bounds", "missing" or replay, etc., must be to in a timely manner, once the call report "out of bounds", "error" or "wipe", the game must be stopped

Athletes are responsible for maintaining their own "home". If they are unable to, they are responsible for dealing with the consequences.

You may restart play if a ball rolls in to your court.

If the player is not satisfied with his / her opponent's behavior or a call, he / she can ask the referee to intervene.
According to the event group training theory, certain sports groups are many similarities, such as table tennis, badminton, tennis, all belong to the racket net-separated competition sports. Tennis project "trust system" application and development has guiding significance for other sports like table tennis, badminton.

Another competition form based on "trust system" is ultimate Frisbee. Even the highest level of competition, ultimate Frisbee in both rules of the game and lack of referee different from traditional sports competition systems. The most important principle is to respect the opponent. Participating in of ultimate Frisbee can greatly improve the participants' social norms and compliance. And sports similar to ultimate Frisbee, such as football, basketball, soccer, can help us learn how ultimate Frisbee implements the "trust" system ".

Currently, measuring this type of project, the rank of the project, performance needs of the referee according to specific rules and scoring methods, performance of the athletes for scoring, require for the consideration.

\section{Discussions on the Findings}

The" trust system" was introduced into college sports in order to reform and innovate in traditional sports competitions, and has had a profound influence on our country's universities sports competition system. It not only increases the content of sports events, but also improves the usefulness of sports competitions fun, broadening the general game features and has an important significance in enhancing physical fitness for college students, cultivating healthy psychology, shaping tenacious will, raising cooperation consciousness, team spirit and the ability to socially adaptation [2]. Considering using the project average colleges and universities could improve the student's understanding in a social interaction. When students participate in the "trust system", it can have a psychological impact, helping them reconsider problems, and give inspiration to life.

\section{Conclusions}

The "trust system" is a type of heuristic education approach, along with comprehensive psychological training, guiding individuals to obtain high achievement, the trainee will apply the strategies from the training to solve problems found in other areas of life, and then improve their overall attitude. Sports rules and the interest of students have helped the "trust system" develop a good foundation. Good venues and equipment condition also provides support for colleges and universities to carry out the "trust system". For these reasons, it is necessary to rapidly implement the "Trust system" into college sports. "Trust system" not only allows students to experience the value and effect previously didn't exist in traditional sports, but also improves conventional sports competitions, and is a new bright feature in university sports events. Through cognitive emotional and social interaction activities with reasonable use of curriculum resources, trust environments can help students fully explore their potential. It can also improve their relationships and mental health interest [24]. Moreover, it has been demonstrated that sports, both as the content and means, form the basic elements to build harmonious relationships, which play a very important role in reducing tension, conflict resolution, as well as building successful interpersonal relationships [22].

\section{Acknowledgments}

This work was supported by Fundamental Research Funds for the Central Universities (DUT15QY47). 


\section{References}

[1] WangYan. The Far East Games and the development of modern East Asian Society: Soochow University doctor; 2014.

[2] HuangJiaxin. Research on the criminal law regulation of the injury behavior of competitive sports: Hebei Pedagogical University master; 2014.

[3] ZhuWenying. On the legal responsibility of the judges. Journal of Beijing Sport University. 2009: 45-8.

[4] GengLei, LvYuping, Department of public physical education, Luoyang Pedagogical University. Research on the causes, evolution tendency and Control Countermeasures of the athlete's deviant behavior. Journal of Tianjin University of Sport. 2014: 221-5.

[5] Hu, A., A loosening tray of sand? Age, period, and cohort effects on generalized trust in Reform-Era China, 1990-2007. Social Science Research, 2015. 51: p. 233-246.

[6] PangTongtong, SongFengning Department of psychology, Guangxi Pedagogical University. Research on interpersonal trust of College Students. Social Psychological Science. 2006: 63-6.

[7] LinChongde, Department of psychology, Faculty of social development, Central University of Finance and Economics. The influence of theme situation and trust characteristics on College Students' trust circle. Psychological development and education. 2013: 255-61.

[8] ZhangDan, Sun Liangdong. The influence of mobile phone addiction on College Students' interpersonal communication. Journal of Southeast University (PHILOSOPHY AND SOCIAL SCIENCES). 2015: 158-60.

[9] ChenJianmei. The influence, causes and reconstruction of College Students' Interpersonal Trust Crisis. Journal of Yunnan Administration College. 2010: 156-8

[10] XiaMian, ZhangYu, XieBaoguo hua, Institute of sociology, Wuhan Academy of Social Sciences, School of labor and human affairs, Renmin University of China. The influencing factors and coping strategies of College Students' behavior dilemma. Study and Practice. 2015: 135-40.

[11] XiaMian, WangYuanwei, HuaQinghu, School of public administration, Huazhong Normal University. - regulation of interpersonal trust affect the state of empathy, the degree of safety situation on helping behavior. Journal of Huazhong Pedagogical University (HUMANITIES AND SOCIAL SCIENCES). 2015: 168-76.
[12] ZhaoWenlong, WangXiazheng xi. Research on the trust problem of Contemporary College Students -- Based on the investigation of a university. Journal of Xi'an Jiao Tong University (SOCIAL SCIENCE EDITION). 2012: 120-8.

[13] WangQing zhong. The current situation of College Students' interpersonal trust and Its Educational Countermeasures. Journal of the National Institute of Education Administration. 2011: 83-7.

[14] ZhangZhonghua. Research on the influence of Outward Bound Training on individual social ability: Shanghai Jiao Tong University master; 2009.

[15] HuangHuijie. An analysis of the positive emotions and interpersonal trust of College Students -- a case study of college students in Xiamen. Contemporary sports science and technology. 2014: 104-5.

[16] ShenWeihua. Analysis on the influence of basketball culture on College Students' interpersonal communication ability. Journal of Yunyang Teachers'College. 2013: 90-2.

[17] ShiZhengxiong. Cheerleading training on female college freshmen mental health and social anxiety. Journal of Wuhan Sports Institute. 2012: 79-82.

[18] ChenXin, YaoMengping. Tracing the psychological connotation of Outward Bound Training: trust and cooperation. Journal of North China University of water resources and hydropower (SOCIAL SCIENCE EDITION). 2014: 148-51.

[19] YangYong. The establishment and test of the interpersonal communication questionnaire of sports teams. Journal of JiLin Institute of Physical Education. 2011: 3-5.

[20] YuShaoyong, HanJian, XieWeiping xi, China Europe International Business School, College of physical education, Qinghai Pedagogical University. The measurement of basketball players' trust in teammates and the relationship with related variables. sports science. 2009: 30-8.

[21] XieYubo, HuoYan. The intervention of sports prescription and group psychological counseling on social anxiety of College Students. Journal of sports adult education. 2013: 40-3.

[22] CaoJingchuan, ChangNaijun. On the value of sports in the construction of harmonious interpersonal relationship. Jorunal of Physical Education Institute of Shanxi Teachers University. 2013: 40-3.

[23] ZhangWei. On trust system. Tennis. 1997: 29-30.

[24] XueYong. Research on Outward Bound Training in College Public Physical Education. Sports science and technology document Bulletin. 2010: 13-5. 